NBER WORKING PAPER SERIES

TIME PREFERENCE AND HEALTH:

AN EXPLORATORY STUDY

Victor R. Fuchs

Working Paper No. $\underline{539}$

NATIONAL BUREAU OF ECONOMIC RESEARCH

1050 Massachusetts Avenue

Cambridge MA 02138

August 1980

This research was supported by grants from the Robert Wood Johnson Foundation and the Henry J. Kaiser Family Foundation. Phillip Farrell provided research assistance and made many valuable suggestions. The participants in the Stanford University Interdisciplinary Seminar in Decision Analysis offered stimulating comments, and at an early stage I benefited from discussions with Martin Seligman and Richard Thaler. Helpful comments from the participants in the NBER Conference "Economic Aspects of Health" are also gratefully acknowledged. The contributions of many other colleagues are indicatd in the references and notes. The research reported here is part of the NBER's research program in Health Economics. Any opinions expressed are those of the author and not those of the National Bureau of Economic Research. 
TIME PREFERENCE AND HEALTH: AN EXPLORATORY STUDY

\begin{abstract}
This paper reports the results of an exploratory survey designed to measure differences in time preference across individuals and to test for relationships between time preference and schooling, health behaviors, and health status. Approximately 500 adults age 25-64 were surveyed by telephone. Time preference was measured by a series of six questions asking the respondent to choose between a sum of money now and a larger sum at a specific point in the future. Approximately two-thirds gave consistent replies to the six questions. The implicit interest rate revealed in their replies is weakly correlated with years of schooling (negative), cigarette smoking (positive), and health status (negative). Family background, especially religion, appears to be an important determinant of time preference.
\end{abstract}

Victor R. Fuchs

National Bureau of Economic Research 204 Junipero Serra Boulevard Stanford, California 94305

$415 / 326-7160$ 


\section{TIME PREFERENCE AND HEALTH: AN EXPLORATORY STUDY}

\section{Victor R. Fuchs}

\section{Introduction}

This paper reports the results of an exploratory effort in a new area--the relationship between intertemporal choice, health behavior, and health status. Intertemporal choice (or time preference) is, of course, a subject much discussed by economists and psychologists. ${ }^{1}$ There is also a large literature on individual behavior (e.g., cigarette smoking, diet, exercise) and health status. ${ }^{2}$ This paper, however, seems to be the first to attempt to bring these subjects together and to test empirically for possible interrelations.

The first section of the paper reviews briefly some of the considerations that suggest that an investigation of time preference might throw light on health behavior and health status. These include empirical studies of the relation between schooling and health, epidemiological investigations of the health effects of cigarette smoking, diet, exercise, and the like, and theoretical issues concerning investment in human capital, imperfections in capital markets, and optimizing behavior.

The second section considers the critical problem of the measurement of time preference and reviews some recent efforts by other investigators to measure time preference in contexts other than health. I then describe a pilot questionnaire given to 500 men and women and present the results of correlation and regression analyses of their replies. The paper concludes with a discussion of questions raised by this exploratory research. 


\section{Background}

Empirical considerations. Cross-sectional studies of the determinants of health status in the United States usually report a strong association between health and years of schooling. This result typically appears regardless of whether health is measured objectively (e.g., mortality rates) or subjectively (e.g., self-evaluation), and is equally robust in studies of differences across groups (e.g., states or cities) or across individuals (e.g., household survey data). Simple correlations between health and years of schooling are usually significant in both the statistical and the practical sense. Furthermore, the relation remains strong after controlling for other variables such as income.

Probably the most thorough investigation of this relationship has been carried out by Michael Grossman in "The Correlation betwoen Health and Schooling" [1975]. This study of middle-aged men is particularly notable for two reasons.

First, a statistically significant effect of schooling on health remains after controlling for a large number of other variables, including family background, health status in high school, income, job satisfaction, and scores on physical and mental tests taken by the men when they were in their early twenties.

Second, all of the men had at least a high school diploma; the mean level of schooling was over 15 years. Grossman's finding that the favorable effects of additional schooling persist even at high levels of schooling is in sharp contrast to the relation between income and health, which is positive at low levels of income but seems to be much weaker or nonexistent at average or high levels [Auster, Leveson and Sarachek, 1969]. 
While the relationship between schooling and health seems well established, the mechanism(s) through which schooling affects health is less clear. Grossman has interpreted the empirical results as support for a household production function model; additional years of schooling make the individual a more efficient producer of health. This efficiency may come through wiser use of medical care or, what is more likely, through differences in cigarette smoking, diet, and other elements of "life style."

The view that "the greatest potential for improving the health of the American people.. . is to be found in what people do and don't do to and for themselves" [Fuchs, 1967] has gained widespread acceptance in recent years as the result of numerous studies by epidemiologists and social scientists interested in health. ${ }^{2}$ These studies report significant differences in health status and in life expectancy associated with such factors as cigarette smoking, diet, and exercise. Not only is a statistical correlation well established, but in many instances there is some understanding of the causal mechanisms as well, e.g., the role of diet and exercise in the prevention of atherosclerosis. What is not understood at all well is the cause of individual variation in health-related behavior.

From an economic point of view many of these behaviors have a common characteristic--they involve trade-offs between current costs and future benefits. The costs may be purely psychic, such as the loss of pleasure from not eating a rich dessert or not smoking a cigarette. They may involve time, such as time for jogging, or they may involve other costs including financial and nonfinancial resources. The expected benefits typically take the form of reductions in the probability of morbidity and mortality from one or more diseases sometime in the future. 
Theoretical considerations. The acceptance of a current cost for a future benefit constitutes an investment. Becker's development of the theory of investment in human capital [Becker, 1964] and Grossman's application of this theory specifically to health [Grossman, 1972] provide a convenient framework for thinking about these health behaviors. Suppose individuals differ in their willingness or ability to undertake investments, i.e., they have different time preferences. Such differences might help to explain variations in cigarette smoking, diet, and the like. Furthermore, this approach suggests possible links with the health-schooling relationship that has been found by so many investigators.

There are at least two ways that individual variation in time preference could explain the correlation between schooling and health. ${ }^{3}$ First, suppose that differences in time preference are established early in life, are relatively stable, and affect subsequent behavior. 4 These differences might be due to differences in the education or income of parents, the stability of the family, the values associated with different religions, or to other background characteristics. Given variation in time preference, it would not be surprising to observe that individuals with low rates of time discount would invest in many years of schooling and would also invest in health-enhancing activities. On this view schooling has no direct effect on health; the observed correlation is due to both schooling and health being functions of time preference.

A second possibility (the two explanations are not mutually exclusive) is that schooling actually affects time preference; those with more schooling are more willing to invest at a lower rate of return. 5 Thus more schooling could result in better health by increasing investments 
in health. The empirical portion of this paper, based on a single crosssection survey, cannot distinguish between these two hypotheses, but we can test for possible relations between schooling and time preference.

Empirical investigation of time preference through survey questions designed to elicit marginal rates of time discount depends critically on capital markets being "imperfect." If capital markets were "perfect" (i.e., if individuals could borrow and lend without limit at a single market rate of interest) marginal rates would be equal for all regardless of time preference. Differences across individuals in time preference might still result in differences in non-tradeable health-related activities, but these would not be predictable from the replies to interest rate questions. However, if capital markets are not "perfect" (an assumption of this paper), individuals may well have different rates of interest at the margin and these may be related to health behavior and health status.

Let us imagine a two-period world. Suppose utility in each period depends upon consumption of goods $(G)$. Utility in the first period also is a function of some activity $C_{1}$ (for simplicity assumed to be free with respect to $G$ ) which affects health (and therefore utility) in period two. For example, $C_{1}$ might be cigarette smoking:

$$
\begin{aligned}
& \mathrm{U}_{1}=\mathrm{U}_{1}\left(\mathrm{G}_{1}, \mathrm{C}_{1}\right) \\
& \mathrm{U}_{2}=\mathrm{U}_{2}\left(\mathrm{G}_{2}, \mathrm{H}_{2}\right) \text { where } \mathrm{H}_{2}=\mathrm{H}\left(\mathrm{C}_{1}\right) .
\end{aligned}
$$

A wealth compensated increase in the rate of interest ( $r$ ) will, ceteris paribus, alter the allocation of wealth between $G_{1}$ and $G_{2}$. But if 
the marginal utility of $C_{1}$ depends on the quantity of $G_{1}$ (and the marginal utility of $\mathrm{H}_{2}$ depends on the quantity of $\mathrm{G}_{2}$ ), the change in $r$ will also affect $\mathrm{C}_{1}$ (and $\mathrm{H}_{2}$ ). If $\mathrm{G}_{1}$ and $\mathrm{C}_{1}$ (and $\mathrm{G}_{2}$ and $\mathrm{H}_{2}$ ) are substitutes, an increase in $\mathrm{r}$ will lead to an increase in $\mathrm{C}_{1}$ and a decrease in $\mathrm{H}_{2}$. If the relationship is complementary (which seems less plausible to me), the reverse would be true.

It should be emphasized that (given imperfect capital markets) differences across individuals in marginal rates of interest can be the result of differences in underlying preference functions (indifference curves) or differences in opportunities to borrow and lend. ${ }^{6}$ In general, it will not be possible to distinguish between these sources empirically, although controlling for family income (as a proxy for "opportunities") may move the analysis somewhat closer to a focus on preference functions per se.

Because time preference is probably only one of many factors affecting the demand for cigarettes, jogging, etc., we can hardly expect perfect correlation among these activities. Differences in time preference across individuals, however, should result in some positive correlations among various health-related behaviors. 


\section{Measurement of Time Preference}

In recent years there have been several attempts to measure time preference through household survey techniques. The objectives of the investigators have varied greatly, but the general approach has been similar. The respondent is typically conf ronted with a hypothetical situation involving different sums of money at different points in time and is asked to express a preference which will implicitly reveal a rate of time discount. A brief review of four such studies follows.

Thomas and Ward [1979]. Psychologists Ewart A. C. Thomas and Wanda E. Ward were interested in looking for relations between time preference and various psychological measures of temporal orientation and measures of optimism or pessimism. They were also interested in possible effects of time preference on saving and spending behavior. Their sample consisted of 63 college students who were asked 24 "open ended" time preference questions of the following type:

If offered $\$ 100$ now or $X$ dollars in six months, what would be the smallest amount of money ( $X$ dollars) you would accept rather than the immediately available $\$ 100$ ?

Some questions gave the future amount and asked the respondent to choose a current value; others gave both amounts and asked for the time period that would make them commensurate. Still others were formulated as payments 
rather than as receipts, and some were expressed in terms of goods rather than simply dollar amounts.

Implicit discount rates were found to be negatively correlated with future time orientation and positively correlated with "big spending." The group results were considered satisfactory, but the measurement of time preference was "disappointing" to the authors because of the "high instability of parameter estimates for individual subjects."

West (SRI) (1978). Economists involved in the Seattle-Denver income maintenance experiment were interested in time preference because the bias introduced by the finite length of the experiment (compared to a national program of indefinite life) would vary depending upon the household's rate of time discount [Metcalf, 1974]. The families in the experiment (more than 1500 in each city) were asked a large number and variety of time preference questions. Some were open-ended, similar to those of Thomas and Ward. Some were "cascades" of the following type:

Suppose you had a choice between a cash bonus of $\$ 100$ today and $\$ 200$ a year from now; which would you choose?

If the respondent chooses $\$ 200$, the question is repeated, with $\$ 175$ substituted for $\$ 200$, and so on until the respondent chooses $\$ 100$. Some cascade questions go up instead of down; some involve payments rather than receipts; and some involve different time periods.

The mean interest rates implicit in the replies of these low income respondents were typically quite high, but the correlation between questions was typically low $(r=$ about .1 or .2$)$. The author (Richard $w$. West) expressed some concern that "the measures are not reliable" (p. 23). Maital and Maital [1978]. A paper by an economist and a psychologist, Shlomo Maital and Sharona Maital, reviews some of the economic 
and psychological literature on time preference and reports the results of a survey of 515 Israeli adults. The Maitals' focus is on the role of time preference in the intergenerational transmission of income inequality. They asked one cascade question involving choice between a sum of money now and higher sums one year from now. A similar question in which gift certificates for a week's shopping at a supermarket were substituted for money was asked in an attempt to measure the "real" as opposed to the nominal implicit rate of interest.

The implicit interest rate was negatively correlated with years of schooling $(\mathrm{r}=-.08)$ and with a dummy variable which took a value of one if the subject and the subject's father were born in Israel $(r=-.12)$. The nominal rate was negatively correlated with income $(r=-.14)$, but the real rate was not. The authors concluded that the ability to defer gratification is part of the process of socialization and that "after adolescence the propensity to delay gratification is quite stable" (p. 192). This may be correct, but it is not clear that the conclusion follows from their results.

Thaler (1979). In a questionnaire administered ${ }^{8}$ to approximately 75 college students, Richard Thaler posed a large number of open-ended money choices primarily to learn how the implicit interest rate varies with the amount of money involved, the time period, the starting point of the comparison, and whether the choice involves receipt or payment. He found that the implicit rate was lower the larger the amount of money and the longer the time period. Also, choices involving two points both in the future typically invoked a smaller implicit interest rate than choices involving the present versus the future. He concluded that there is a 
"psychic fixed cost" to waiting, as well as a cost that varies with amount and time.

I included a few questions on health status in the Thaler questionnaire and found a significant negative correlation between health and median implicit interest rate across individuals. This result led me to undertake a larger pilot survey described in the next section.

The Pilot Survey

A pilot survey was conducted in November 1979 under the direction of Stephen and Ann Cole with the objective of measuring time preference, health status, and health behavior as well as a large number of family background and current socioeconomic variables. ${ }^{9}$ Telephone interviews approximately 20 minutes in length were conducted with 508 individuals living in Nassau and Suffolk Counties (on Long Island just east of New York City). Respondents were selected through a random sample of telephone

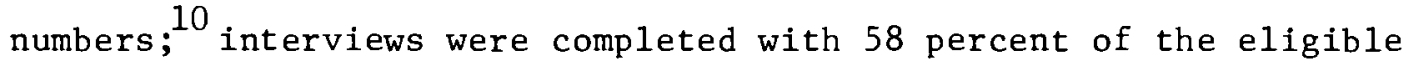
respondents. The characteristics of the respondents conformed closely to Census data for those two counties, but the possibility of selection bias remains, especially with respect to some of the family background variables. The sample was restricted to individuals aged 25-64, and interviewers were instructed to obtain an approximately equal distribution between female and male respondents. The respondents differ from a national sample with respect to religion (55 percent Catholic and 17 percent Jewish), race ( 3 percent $B l a c k$ ), and schooling (about one year above the national average). They are also somewhat more affluent and in slightly better 
health. Allowing for the predominantly suburban middle-class character of the two counties, the distributions of replies on the health, health behavior, family background, and socioeconomic variables conform closely to those obtained in national surveys.

The principal approach to the measurement of time preference was through a series of six questions asking the respondent to choose between a sum of money now and a larger sum at a specific point in the future, 11 e.g., "Would you choose $\$ 1500$ now or $\$ 4,000$ in five years?" The amount and the time period varied, as did the interest rate implicit in each question. The lowest implicit rate was 10.1 percent per annum (continuously compounded); the highest was 51.1 percent. This dichotomous choice type of question was used because it was deemed simpler for the respondent than the open-ended or cascade type questions discussed previously. ${ }^{12}$

In addition to the implicit interest rate series of questions, a cascade type question with an explicit interest rate (beginning at 6 percent and rising to 50 percent) was asked. The survey also included four attitudinal questions, e.g., "Do you agree or disagree with this statement: It makes more sense to spend your money now rather than saving it for the future." Also, each respondent was asked to choose an expected rate of change of prices for the coming year. The final time preference questions dealt with the respondent's use of credit when purchasing a car or through unpaid balances on bank credit cards.

The questions dealing with family background, socioeconomic status, health behavior and health status are similar to those usually asked in household surveys. Only some of these variables have been analyzed thus far. They will be discussed in the next section on empirical results. 
Empirical Results

One of the purposes of the pilot survey was to determine whether respondents would, in a brief telephone interview, give sensible answers to hypothetical money choice questions when the interest rates implicit in the questions are far from transparent. The data presented in Table 1 suggest that many respondents do give sensible replies; some do not. The six implicit interest rate questions ask the respondent to choose between taking a smaller prize now or waiting for a larger prize. A priori we expect the fraction of respondents taking the prize now to diminish as the implicit interest rate rises. Table 1 shows that this did occur. For the sample as a whole, 76 percent chose "now" for the question with an implicit interest rate of 10.1 percent per annum, and only 33 percent did so when the implicit interest rate was 51.1 percent.

Not only do the group results conform to a priori expectations, but almost two-thirds of the respondents gave replies which were internally "consistent" for each individual. A set of replies was defined as consistent if the respondent never answered "now" to a question with an implicit interest rate that was higher than the rate in another question to which the answer was "wait."13 The last three columns of Table 1 show results for the sample divided into three groups: those with consistent answers, those whose answers would be consistent if one reply were reversed (about onefourth of the sample), and those respondents whose replies require two or three reversals in order to achieve consistency (about 10 percent of the sample). ${ }^{14}$ The relation between the fraction taking the prize now and the implicit interest rate is much weaker for those respondents with inconsistent answers and much stronger for those with consistent answers. 
Table 1. Mean probability of taking prize now, by implicit compound interest rate and number of inconsistent answers.

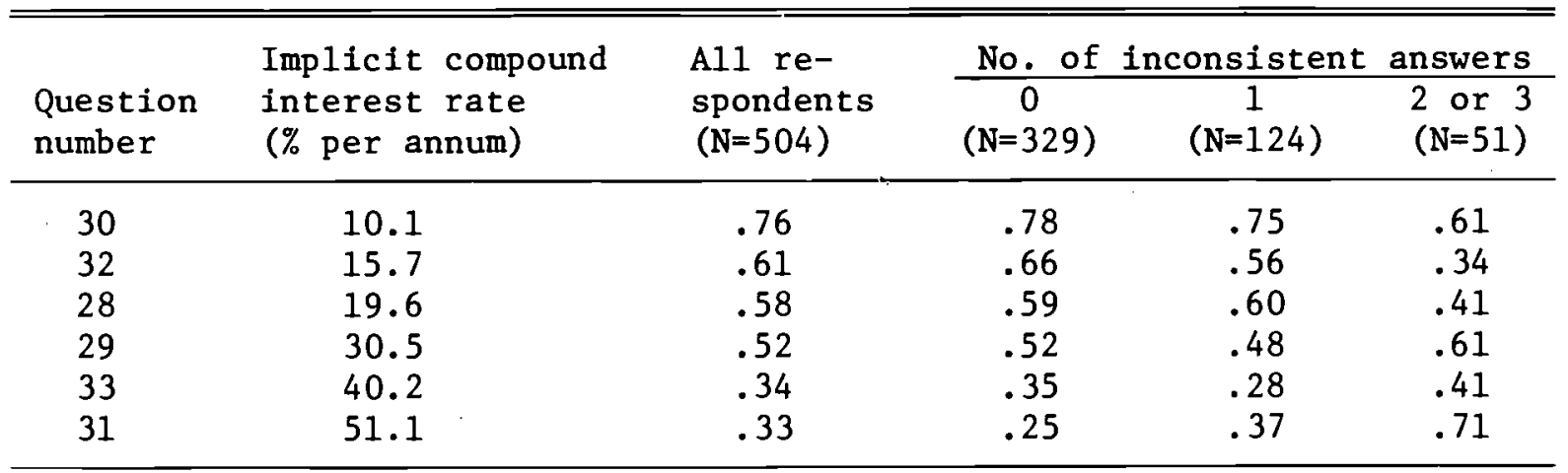

Table 2. Regressions of probability of taking prize now on interest rate variables, by number of inconsistent answers.

\begin{tabular}{|c|c|c|c|c|}
\hline & \multirow{2}{*}{$\begin{array}{l}\text { Al1 re- } \\
\text { spondents }\end{array}$} & \multicolumn{3}{|c|}{ Number of inconsistent answers } \\
\hline & & 0 & 1 & 2 or 3 \\
\hline $\mathrm{N}$ & 2952 & 1956 & 719 & 277 \\
\hline $\mathrm{R}^{2}$ & .106 & .158 & .082 & .026 \\
\hline Intercept & $\begin{array}{l}.733 \\
(.022)\end{array}$ & $\begin{array}{l}.783 \\
(.026)\end{array}$ & $\begin{array}{l}.733 \\
(.046)\end{array}$ & $\begin{array}{l}.414 \\
(.074)\end{array}$ \\
\hline $\begin{array}{l}\text { Question compound } \\
\text { implicit interest } \\
\text { rate (\% per annum) }\end{array}$ & $\begin{array}{l}-.0073^{* *} \\
(.0012) \\
{[-.0071]}\end{array}$ & $\begin{array}{l}-.0111^{* *} \\
(.0014) \\
{[-.0126]}\end{array}$ & $\begin{array}{l}-.0037 \\
(.0024) \\
{[-.0034]}\end{array}$ & $\begin{array}{l}.0106^{*} \\
(.0040) \\
{[.0135]}\end{array}$ \\
\hline $\begin{array}{l}\text { Question simple } \\
\text { implicit interest } \\
\text { rate (\% per annum) }\end{array}$ & $\begin{array}{c}-.0017^{* t} \\
(.0006) \\
{[-.0020]}\end{array}$ & $\begin{array}{l}-.0008 \\
(.0007) \\
{[-.0007]}\end{array}$ & $\begin{array}{l}-.0032^{* *} \\
(.0011) \\
{[-.0037]}\end{array}$ & $\begin{array}{r}-.0042^{*} \\
(.0019) \\
{[-.0053]}\end{array}$ \\
\hline $\begin{array}{l}\text { Respondent explicit } \\
\text { interest rate } \\
\text { (\% per annum) }\end{array}$ & $\begin{array}{l}.0054 * * \\
(.0008) \\
{[.0064]}\end{array}$ & $\begin{array}{l}.0068^{* \star} \\
(.0009) \\
{[.0090]}\end{array}$ & $\begin{array}{l}.0020 \\
(.0019) \\
{[.0019]}\end{array}$ & $\begin{array}{l}.0010 \\
(.0025) \\
{[.0010]}\end{array}$ \\
\hline
\end{tabular}

Notes: Regressions based on person-question observations.

The OLS regression coefficients are shown first with their standard errors in parentheses below. The marginal effects (at mean probability) from the logistic regressions are in brackets.

${ }^{*} \mathrm{p}<.05$

${ }^{*} \mathrm{p}<.01$ 
Most of the results reported in this paper are based on analyses limited to those respondents with consistent replies.

Table 2 presents the results of regressions in which each question to each individual is treated as an observation. When the regressions are run OLS, the dependent variable is dichotomous, taking a value of $I$ if the reply is "now" and 0 if it is "wait." The right-hand-side variables are the compound interest rate implicit in each question, the simple implicit interest rate, and the individual's explicit interest rate given in reply to the cascade question mentioned in the previous section. We see that the probability that a given individual will reply "now" to a given question falls sharply as the interest rate implicit in the question rises, and rises rapidly as the individual's explicit interest rate rises. These results hold for the entire sample and are particularly strong for those respondents classified as consistent, but do not hold for the other respondents. Logistic regressions estimated by a maximum likelihood procedure give similar results when evaluated at the mean probability of taking "now." (See marginal effects in brackets.)

The contrast between the compound interest rate and the simple interest rate coefficients, depending upon the consistency class, suggests one possible reason why some respondents give inconsistent replies. ${ }^{15}$ The two interest rates are, of course, highly correlated, but not perfectly so. Those giving consistent replies seem to have been influenced by the implicit compound rate, while those with the most inconsistent replies seem to have been influenced primarily by the simple rate. We also see that there is a close connection between the explicit rate and the probability of choosing "now" for the consistent individuals, but not for those whose replies to the implicit rate questions were inconsistent. 
Inasmuch as these results are based on replies to only six questions, they can only be suggestive, not definitive. It would be desirable to see if the distinction between the compound and simple interest rate holds up in a survey based on a large number of questions. For this sample, this distinction gives stronger results than do regressions based on Thaler's hypotheses about the effects of length of time or amount of money on the willingness to wait.

Table 3 reports the results of regressions similar to those in Table 2, but designed to measure the effects of individual characteristics on the probability of the individual choosing "now" in response to the implicit interest rate questions. The regressions are limited to respondents with consistent replies and are run separately for females and males because preliminary analysis revealed significant interaction effects for some variables. A brief discussion of the additional variables follows:

AGE: Respondents placed themselves in one of four age categories: 25-34, 35-44, 45-54, or 55-64. The mid-point of each category was used to construct a continuous variable. There was no a priori expectation for this variable. Maital and Maital had found a positive correlation between age and the "real" interest rate $(r=.10)$, but no relation with the nominal rate.

PARED: Parents' education is the mean of the years of schooling of the respondent's mother and father. The separate schooling variables are highly correlated, and do not yield any significant information when included separately. A priori I expected a negative coefficient for PARED, at least prior to inclusion 


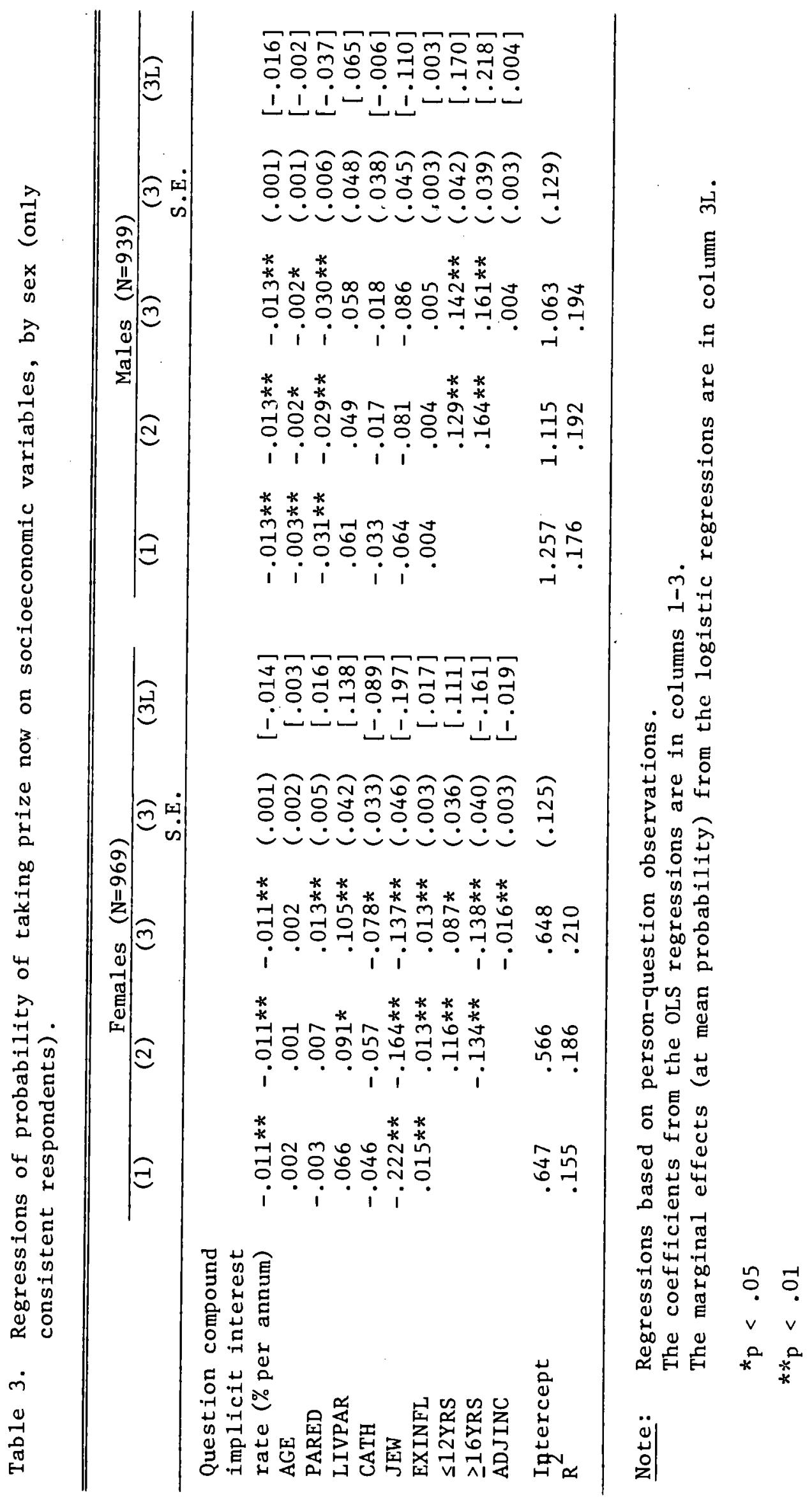


of other variables that are also affected by PARED, e.g., the respondent's own years of schooling.

LIVPAR: This is a dummy variable taking a value of 1 if the respondent lived with both parents until age $16 ; 0$ otherwise. Some of the psychological literature suggest that this coefficient should be negative, i.e., should work much the same way as PARED.

CATH,JEW: These are dummy variables taking a value of 1 if the respondent is Catholic (or Jewish), and 0 if Protestant or other.

EXINFL: Expected inflation is a continuous variable derived from the respondent's reply to the question about expected price change during the coming year. A positive coefficient is expected when the implicit interest rate is held constant. At any given nominal rate, the respondent should be less willing to wait if prices are expected to rise rapidly because the implicit "real" rate of interest is lower.

$\leq$ I2YRS These are dumny variables for the respondent's own years of and $\geq 16$ YRS: schooling. The omitted class is those with 13 to 15 years. A positive coefficient is expected for $\leq 12 Y R S$, and a negative one for $216 \mathrm{YRS}$, for reasons discussed in the first section of this paper.

ADJINC: Adjusted family income is a continuous variable derived as follows. The respondent placed total family income in one of the following categories: under $\$ 15,000, \$ 15,000$ to $\$ 25,000$, $\$ 25,000$ to $\$ 35,000$, or over $\$ 35,000$. Values of $10,20,30$ and 40 were assigned to each category. Sixty of the respondents did not answer the income question. An income category was 
assigned to them on the basis of their reply to a social class question and a regression of income on social class. Total family income was divided by "adult equivalents" to create adjusted family income. "Adult equivalents" is the weighted sum of the number of adults and the number of children in the household with the following weights: respondent $=1$; each additional adult $=.8 ;$ first child $=.5 ;$ second child $=.4$; each additional child $=.3$. A negative coefficient was expected for ADJINC both because of a possible effect of income on time preference, and an effect of time preference on income. 16

Three alternative OLS specifications (for each sex) allow us to look first only at the background variables (controlling for the implicit interest rate and expected inflation), then at the effects of schooling (which is probably affected by the family background variables and may be a route through which they affect time preference), and finally at the effect of family income. The regressions were also estimated in logistic form by maximum likelihood; the results are similar to those for oLs. The coefficients from the logistic version of the third specification, converted to marginal effects at the mean probability of taking "now" are shown in column (3L).

In the first specification, AGE and PARED are statistically significant for males in the expected direction, while JEW is highly significant for females. A coefficient of -.22 indicates that, ceteris paribus, a Jewish female respondent has .22 lower probability of answering "now" than does a Protestent (or other) female. The sign of the LIVPAR coefficient is opposite to that expected, perhaps because of sample 
selection bias. It may be that most persons from broken homes do have high rates of time discount, but those who "make it" to a middle class suburban community are probably atypical and may have low rates of time discount.

The schooling variables behave as expected for females and are highly significant. For males, the $\leq 12$ YRS coefficient is as expected, but the $\geq 16$ YRS coefficient has the "wrong" sign and is statistically significant. It is not obvious why men with 16 years of schooling or more should be, ceteris paribus, more eager to take the prize now than men with 13 to 15 years; possibly the former have better opportunities to invest the money.

The income variable works as expected for females and is significant; it has the wrong sign for males but is not significant. In the fullest specification, LIVPAR and PARED are statistically significant for females with signs opposite to that expected. Some of the background and socioeconomic variables are highly correlated with one another (see Appendix Table A for the zero order correlation matrix) and multicollinearity may explain some of the perverse results. EXINFL is statistically significant in the expected direction and has approximately the same effect as the nominal implicit interest rate on the probability of taking the prize now.

The model underlying the regressions reported in Table 3 treats time preference (as reflected in the choice between "now" and "wait") as dependent on years of schooling. As previously discussed, some writers believe that differences in time preference are established early in life and are stable. They would treat years of schooling as dependent on time 
preference. Table 4 presents the results of regressions in which years of schooling is regressed on time preference and other variables. The new variables are:

IMPINT: An implicit interest rate is calculated for each respondent who gave consistent answers to the six implicit interest rate questions. Those respondents who answered "now" to some questions and "wait" to others were assigned a rate equal to the mean of the highest implicit rate to which they answered "now" and the lowest to which they answered "wait."17 Those respondents who always chose to "wait" were assigned a rate of 5 percent and those who always chose "now" were assigned 60 percent. The higher the respondent's IMPINT, the lower should be the years of schooling. The variable EXINFL (described previously) should work in the opposite direction.

HSRANK: The respondent's scholastic performance in high school was inferred from replies to the question: "When you were in high school were you: (percent of sample in each category shown in parentheses)

1) an excellent student (10\%)

2) an above average student (28\%)

3) an average student (57\%)

4) a below average student (5\%).

Grade averages of $95,85,75$, and 65 were assigned to the four categories respectively, and the variable is treated as a continuous variable. A positive coefficient is expected.

HSHLTH: Health in high school was treated as a dummy variable taking a value of 1 if the respondent recalled his or her health as being "better than most of the other kids" (26\%), and 0 if it was "about average" 
Table 4. Regression of years of schooling on implicit interest rate and other variables.

\begin{tabular}{|c|c|c|c|c|c|c|c|c|}
\hline & \multicolumn{4}{|c|}{ Females $(\mathrm{N}=162)^{\mathrm{a}}$} & \multicolumn{4}{|c|}{ Males $(\mathrm{N}=157)^{\mathrm{a}}$} \\
\hline & (1) & $(2)$ & (3) & $\begin{array}{c}(3) \\
\text { S.E. }\end{array}$ & (1) & $(2)$ & (3) & $\begin{array}{l}\text { (3) } \\
\text { S.E. }\end{array}$ \\
\hline AGE & $-.066 * *$ & $-.035 * *$ & $-.038 \star$ & $(.016)$ & $-.045 *$ & -.035 & $-.043^{*}$ & $(.017)$ \\
\hline IMPINT & $-.024 * *$ & $-.019 *$ & -.014 & $(.008)$ & -.004 & .003 & -.000 & $(.009)$ \\
\hline EXINFL & -.036 & -.032 & -.031 & $(.029)$ & $.104 *$ & $.106 *$ & $.107 * *$ & $(.040)$ \\
\hline PARED & & $.223 * *$ & $.150 * *$ & $(.056)$ & & .137 & .091 & $(.074)$ \\
\hline LIVPAR & & $1.252 *$ & $1.025 *$ & $(.456)$ & & $1.398 *$ & $1.299 *$ & $(.568)$ \\
\hline CATH & & .082 & -.143 & $(.357)$ & & $-1 \cdot 346 * *$ & $-1.157^{*}$ & $(.460)$ \\
\hline JEW & & $1.276 *$ & $1.077 *$ & $(.488)$ & & .899 & .730 & $(.550)$ \\
\hline HSRANK & & & $.120 * *$ & $(.021)$ & & & $.089 * *$ & $(.027)$ \\
\hline HSHLTH & & & .130 & $(.367)$ & & & .109 & $(.403)$ \\
\hline Intercept & 17. 367 & 12.116 & 3.562 & $(1.951)$ & 15.277 & 12.505 & 6.426 & $(2.351)$ \\
\hline $\mathrm{R}^{2}$ & .128 & .274 & .411 & & .072 & .273 & .324 & \\
\hline
\end{tabular}

${ }^{a}$ Consistent respondents only.

${ }^{*} \mathrm{p}<.05 \quad *{ }^{\mathrm{p}} \mathrm{p}<.01$

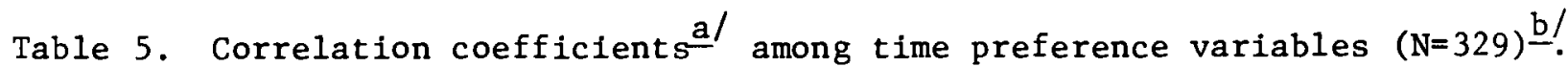

\begin{tabular}{|c|c|c|c|c|c|c|c|c|}
\hline & $\begin{array}{l}\operatorname{Imp} 1 \\
\text { int }\end{array}$ & $\begin{array}{l}\operatorname{Exp} 1 \\
\text { int }\end{array}$ & $\begin{array}{l}\text { Don't } \\
\text { sacrifice }\end{array}$ & $\begin{array}{l}\text { Spend } \\
\text { now }\end{array}$ & $\begin{array}{l}\text { No life } \\
\text { insur }\end{array}$ & $\begin{array}{l}\text { Don't } \\
\text { worry }\end{array}$ & $\begin{array}{l}\text { Credit } \\
\text { card debit }\end{array}$ & $\begin{array}{l}\text { Use car } \\
\text { loan }\end{array}$ \\
\hline Impl interest & -- & $.23 * *$ & .00 & $.23 * *$ & -.06 & $.14 *$ & .09 & .06 \\
\hline Expl interest & $.23 * *$ & -- & .02 & .11 & -.04 & .08 & -.02 & .00 \\
\hline Don't sacrifcl & -.01 & .03 & -- & .08 & $.25 * *$ & .09 & .07 & $.12 *$ \\
\hline Spend nowd & $.23 * *$ & $.11 *$ & $.09 *$ & -- & .03 & .11 & .11 & .04 \\
\hline No life insel & -.06 & -.04 & $.26 * *$ & .02 & -- & -.06 & -.07 & -.01 \\
\hline Don't worryf/ & $.14 * *$ & .08 & $.09 *$ & $.10 *$ & -.05 & -- & .08 & .09 \\
\hline Cr card debit & .09 & -.03 & .07 & $.11 *$ & -.08 & $.09 *$ & -- & $.21 * *$ \\
\hline Use car loan & .06 & .00 & $.13 *$ & .04 & -.01 & $.10 *$ & $.19 * *$ & - \\
\hline
\end{tabular}

$*_{\mathrm{p}}<.05 \quad * *_{\mathrm{p}}<.01$

a/ Upper right triangle shows simple correlations; lower left triangle shows partial correlations controlling for age and sex.

b/ Only respondents with consistent answers to implicit interest rate questions.

c/ Disagree with statement in question 35 .

d/ Agree with statement in question 36 .

e/ Disagree with statement in question 37 .

fl Agree with statement in question 38 . 
$(70 \%)$ or "worse than most of the other kids" (4\%). A positive coefficient is also expected for this variable.

The results of these regressions again give weak support for the view that there is a relation between time preference and schooling, but leave open the question of the direction of the causality. In the first specification the coefficient of IMPINT is highly significant for females and is still significant when the family background variables are introduced. EXINFL has the wrong sign and is not significant. For males the reverse is true. EXINFL is significant with the expected sign, but IMPINT shows no effect.

The background variables work as expected, with PARED and LIVPAR both raising years of schooling. HSRANK has a very strong effect, but the causality may be partly the reverse of that assumed in this regression, i.e., persons who plan to go on to college may exert more effort to do well in high school. HSHLTH shows practically no effect on years of schooling. In general, this variable has very low correlations with other socioeconomic or health variables, suggesting that it may be poorly measured.

One of the purposes of the pilot survey was to determine the correlation among alternative measures of time preference. These correlation coefficients, shown in Table 5, indicate a weak but statistically significant correlation between the implicit and explicit interest rates and between the implicit rate and replies to the two simple attitudinal questions ("spend now" and "don't worry"). The other two attitudinal questions, which are more complex because they introduce considerations such as life insurance and the education of children, do not correlate 
well with either the implicit or explicit rates, although they are correlated with each other. The fact that the credit card debit and car loan dummy variables are not significantly correlated with the interest rate variables would be disturbing, but given the timing of the pilot survey, there may be an easy explanation. The interest rates on these loans were legally restricted to unrealistically low levels, given the high interest rates prevailing at that time and given the high rates revealed by the respondents in replies to the implicit rate questions.

Explanations aside, the low correlations across time preference questions must be a source of some concern. They suggest the need for further refinement in the survey techniques and the need to understand better how the specific context of a decision affects intertemporal choice. Do differences in time preference affect investments in health? Some crude measures of these investments were obtained by asking the respondents about their cigarette smoking, dental visits, exercise, weight (as a proxy for diet) and seat belt usage.

Replies to questions about these behaviors were converted to continuous variables as follows:

SMOKE Question: "Do you currently smoke cigarettes?" Replies :

$\begin{array}{ccc}\begin{array}{l}\text { Assigned } \\ \text { value }\end{array} & & \begin{array}{c}\% \text { of } \\ \text { sample }\end{array} \\ 10 & & 64 \\ 20 & & 12 \\ 30 & 14\end{array}$

(1) No.

(2) Yes, less than a pack a day. 2

(3) Yes, about a pack a day. 10 
OVWT Question: "Would you say that you are currently ...

Replies:

(1) . . underweight."

(2) . . about the right weight."

0

5

(3) . . about 5-10 pounds overweight

0

39

(4) . . about 11-20 pounds overweight."

7.5

35

(5) . . more than 20 pounds overweight."

15

12

30

DENTDEL Question: "When did you have your last dental checkup?"

Replies :

(1) Within the last year.

0.5

72

(2) About one or two years ago.

1.5

19

(3) About three to five years ago.

4. 0

5

(4) More than five years ago.

8.0

EXER Question: "How often do you exercise for 30 minutes or more?"

Replies :

(1) Never.

0

40

(2) Once a month or less.

1

9

(3) Several times a month.

2.5

9

(4) About once a week. 10

(5) Two to three times a week.

(6) More than three times a week.

STBELT Question: "When you are in a car, how often do you use seat belts?"

Replies :

(1) All the time.

1.0

21

(2) Most of the time.

(3) Some of the time.

.30

(4) Rarely or never.

.05 
The correlation between favorable health behaviors is positive for every possible pair (reversing signs where appropriate), but the coefficients are quite low and only some are statistically significant (see Table 6). The correlations with seat belt usage suggest that individual differences with respect to health in general may be more important than differences in time preference. Moreover, the generally low correlations underscore the fact that even if there is a common factor at work across behaviors, there are also other factors that are specific to particular behaviors. The low coefficients may also be attributable to the rough approximations used to measure the variables.

In order to test for possible effects of time preference, the health behavior variables were regressed on IMPINT, EXINFL, and several other variables. The results for cigarette smoking are reported in Table 7. They confirm the expectation that cigarette smoking does increase with higher IMPINT, and decrease with higher EXINFL, but the size of the effect of IMPINT is quite small. We also see an effect of schooling on cigarette smoking as expected; the difference between the coefficients for $\leq 12$ YRS and $\geq 16$ YRS is statistically significant for males. The overall explanatory power of the regression is low; most of the variation in cigarette smoking is not explained by these variables and the addition of ADJINC was of little value.

Regressions for the other health behaviors were even less satisfactory. The total explanatory power was low, and IMPINT was not statistically significant except for EXER for males, where the sign was the opposite of that expected. 
Table 6. Correlation coefficients a among health-related behavior variables $(\mathrm{N}=508)$.

\begin{tabular}{lllcll}
\hline \hline & SMOKE & OVWT & DENTDEL & EXER & STBELT \\
\hline SMOKE & -- & .01 & .06 & -.08 & $-.12 * *$ \\
OVWT & .01 & -- & .06 & $-.18 * *$ & $-.12 * *$ \\
DENTDEL & .05 & .06 & -- & -.01 & -.07 \\
EXER & $-.08 *$ & $-.17 * *$ & -.01 & -- & $.09 *$ \\
STBELT & $-.12 * *$ & $-.12 * *$ & $-.08 *$ & $.09 *$ & -- \\
\hline
\end{tabular}

$*_{\mathrm{p}}<.05 \quad * *_{\mathrm{p}}<.01$

a/ Upper right triangle shows simple correlations; lower left triangle shows partial correlations, controlling for age and sex.

Table 7. Regression of number of cigarettes smoked per day on socioeconomic variables.

\begin{tabular}{|c|c|c|c|c|c|c|c|c|}
\hline \multirow[b]{4}{*}{ AGE } & \multicolumn{4}{|c|}{ Females $(\mathrm{N}=162)$ a $/$} & \multicolumn{4}{|c|}{ Males $(\mathrm{N}=157)$ a/ } \\
\hline & $(1)$ & $(2)$ & (3) & (3) & (1) & $(2)$ & (3) & (3) \\
\hline & \multicolumn{3}{|c|}{ Coefficient } & S.E. & \multicolumn{3}{|c|}{ Coefficient } & S.E. \\
\hline & -.041 & -.075 & -.081 & $(.076)$ & .018 & .037 & .025 & $(.080)$ \\
\hline IMP INT & $.072 *$ & $.074 *$ & .063 & $(.036)$ & $.092 *$ & $.098 *$ & $.091 *$ & $(.043)$ \\
\hline EXINFL & $-.280 *$ & $-.297 *$ & $-.292 *$ & $(.136)$ & -.263 & -.275 & -.155 & $(.186)$ \\
\hline PARED & & -.376 & -.313 & $(.268)$ & & .234 & .403 & $(.337)$ \\
\hline LIVPAR & & .117 & -.049 & $(2.139)$ & & -2.887 & -1.326 & $(2.664)$ \\
\hline CATH & & -2.325 & -2.604 & $(1.658)$ & & -.617 & -1.647 & $(2.136)$ \\
\hline JEW & & .092 & 1.012 & $(2.300)$ & & -1.224 & -.758 & $(2.537)$ \\
\hline$\leq 12 \mathrm{YRS}$ & & & -2.089 & $(1.814)$ & & & $5.325 *$ & $(2.315)$ \\
\hline$\geq 16 \mathrm{YRS}$ & & & $-5.568 * *$ & $(2.045)$ & & & -.853 & $(2.207)$ \\
\hline $\begin{array}{l}\text { Intercept } \\
\mathrm{R}^{2}\end{array}$ & $\begin{array}{r}8.606 \\
.043\end{array}$ & $\begin{array}{r}15.284 \\
.067\end{array}$ & $\begin{array}{r}17.595 \\
.110\end{array}$ & $(6.097)$ & $\begin{array}{r}5.759 \\
.043\end{array}$ & $\begin{array}{r}5.577 \\
.054\end{array}$ & $\begin{array}{r}1.102 \\
.108\end{array}$ & $(7.018)$ \\
\hline Dependent variable & mean & & & 6.42 & & & & 6.82 \\
\hline Dependent variable & standard & deviatio & & 9.43 & & & & 10.68 \\
\hline
\end{tabular}

a/ Only respondents with consistent answers to implicit interest rate questions.

$*_{\mathrm{p}}<.05 \quad * *_{\mathrm{p}}<.01$ 
In the first section of this paper questions were raised about whether difference in time preference could help explain health status or throw light on the relation between health status and schooling. Table 8 reports the results of regressions addressed to these questions. Panel A uses as the dependent variable LnHLTH, the same variable used by Grossman [1975] in "The Correlation between Health and Schooling." It is obtained by taking the logarithms of values given to replies to the question "In general, would you consider your health to be...

\begin{tabular}{lccc} 
& Assigned value & & $\%$ of sample \\
\cline { 2 - 2 } Excellent & 1.0 & & 43 \\
Good & 9.8 & & 45 \\
Fair & 26.4 & 9 \\
Poor & 86.7 & 3
\end{tabular}

Grossman obtained these values from a regression of work-loss weeks due to illness on self evaluation of health status. ${ }^{18}$

The results support Grossman's finding of a strong effect of schooling on health and it appears that the effect is equally strong for females and males. ${ }^{19}$ The coefficients for IMPINT have the expected negative sign, but are not statistically significant. When time preference and schooling are entered simultaneously, the latter clearly dominates the former. When ADJINC is added to the regression, its coefficient is not significant, and the other results are unchanged.

Three other sets of health status questions were asked in addition to the subjective self-evaluation. One used a checklist of symptoms and diagnoses; a second requested information on utilization of hospitals, drugs, and physicians' services; and the third asked about the respondent's ability to walk or jog a mile. These measures are significantly correlated with each other and with self-evaluation of health status, even after 
controlling for age and sex (partial correlation coefficients are typically about .20). A composite health status variable MNEXHLTH was calculated from the four measures by assigning a value of .25 to respondents for each of the following: (1) Self-evaluation excellent (44\%)

(2) Zero symptoms (47\%)

(3) Very low medical care utilization ${ }^{20}$ (64\%)

(4) Able to jog a mile (61\%)

This "mean proportion of excellent health measures" is the dependent variable in the regressions reported in Part B of Table 8 . They indicate a stronger effect for time preference and a relatively weaker effect for schooling. ${ }^{21}$ IMPINT actually achieves statistical significance for males. It appears that the choice of health status measure makes a difference.

Unresolved Questions

This exploratory study leaves unresolved many empirical and theoretical questions concerning time preference, health behavior, and health status. The attempt to measure implicit interest rates through a series of six dichotomous choices between "money now" and "money in the future" produced answers that are clearly not all "noise," but neither are they completely satisfactory. About one-third of the respondents had at least one inconsistent reply. Moreover, one-half of those who were "consistent" answered all the questions the same way (either all "now" or all "wait"). An extension of the range of the implicit interest rates might yield more information about this group. An increase in the number of questions would be desirable for many reasons, but the directors of the survey believe that six is about all the respondents will tolerate as part of the total telephone interview. 
Table 8. Regressions of health status ${ }^{a}$ on time preference, schooling and age.

\begin{tabular}{|c|c|c|c|c|c|c|c|c|c|c|}
\hline & \multicolumn{5}{|c|}{ Females } & \multicolumn{5}{|c|}{ Males } \\
\hline & IMPINT & EXINFL & SCHOOL & AGE & $\mathrm{R}^{2}$ & IMP INT & EXINFL & SCHOOL & $\overline{\mathrm{AGE}}$ & $\mathrm{R}^{2}$ \\
\hline \multicolumn{11}{|c|}{ Part A } \\
\hline \multicolumn{11}{|c|}{ LnHLTH } \\
\hline (1) & $\begin{array}{l}-.003 \\
(.003)\end{array}$ & $\begin{array}{l}-.004 \\
(.012)\end{array}$ & & $\begin{array}{c}-.015 * \\
(.006)\end{array}$ & .045 & $\begin{array}{c}-.003 \\
(.003)\end{array}$ & $\begin{array}{l}.018 \\
(.015)\end{array}$ & & $\begin{array}{l}-.021 * \star \\
(.006)\end{array}$ & .084 \\
\hline (2) & & & $\begin{array}{l}.059 * \\
(.025)\end{array}$ & $\begin{array}{l}-.010 \\
(.006)\end{array}$ & .069 & & & $(.059 *$ & $\begin{array}{l}-.020 * * \\
(.006)\end{array}$ & .106 \\
\hline (3) & $\begin{array}{l}-.002 \\
(.003)\end{array}$ & $\begin{array}{l}-.001 \\
(.011)\end{array}$ & $\begin{array}{l}.054 * \\
(.026)\end{array}$ & $\begin{array}{l}-.011 \\
(.006)\end{array}$ & .072 & $\begin{array}{l}-.003 \\
(.004)\end{array}$ & $\begin{array}{l}.013 \\
(.016)\end{array}$ & $\begin{array}{c}.054 \\
(.028)\end{array}$ & $\begin{array}{l}-.020 * * \\
(.006)\end{array}$ & .115 \\
\hline \multicolumn{11}{|c|}{ Part B } \\
\hline \multicolumn{11}{|c|}{ MNEXHLTH } \\
\hline (1) & $\begin{array}{l}-.001 \\
(.001)\end{array}$ & $(.001)$ & & $\begin{array}{l}-.007 * * \\
(.002)\end{array}$ & .062 & $\begin{array}{l}-.002 * \\
(.001)\end{array}$ & $\begin{array}{l}.001 \\
(.005)\end{array}$ & & $\begin{array}{l}-.011 * * \\
(.002)\end{array}$ & .208 \\
\hline (2) & & & $\begin{array}{l}.013 \\
(.010)\end{array}$ & $\begin{array}{l}-.006 * * \\
(.002)\end{array}$ & .071 & & & $\begin{array}{c}.009 \\
(.008)\end{array}$ & $\begin{array}{l}-.011 * * \\
(.002)\end{array}$ & .189 \\
\hline (3) & $\begin{array}{l}-.000 \\
(.001)\end{array}$ & $\begin{array}{l}.002 \\
(.005)\end{array}$ & $\begin{array}{l}.013 \\
(.010)\end{array}$ & $\begin{array}{l}-.006 * * \\
(.002)\end{array}$ & .072 & $\begin{array}{c}-.002 * \\
(.001)\end{array}$ & $\begin{array}{l}.001 \\
(.005)\end{array}$ & $\begin{array}{l}.009 \\
(.008)\end{array}$ & $\begin{array}{l}-.011 * * \\
(.002)\end{array}$ & .214 \\
\hline
\end{tabular}

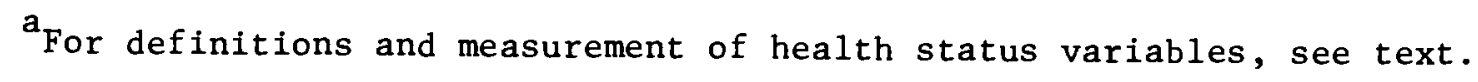

${ }^{*} \mathrm{p} .05$

${ }^{*} \mathrm{p}<.01$ 
At a time of sharply rising prices, the measurement of "real" vs. "nominal" interest rates presents a major problem which is solved only partially by including a question on expected inflation. The EXINFL variable usually works as expected--opposite to IMPINT--but the coefficients are not always equal, and sometimes the signs are inconsistent.

The mean implicit interest rate in this survey of 30 percent per annum is substantially lower than the rates reported in surveys by other investigators. This rate is still high, however, compared to current borrowing and lending rates, and high compared to the mean response to the explicit interest rate question (14 percent). Why the difference? Also, although the implicit and explicit rates are significantly correlated $(r=.23$ for the two-thirds of the sample with consistent replies), why isn't the correlation higher?

The pilot survey confirms our a priori expectation of a correlation between schooling and time preference, but other types of data are needed if we are to learn something about the direction of the causality. The effect of time preference on health behavior and on health status is usually in the expected direction, but is not always statistically significant, and even when statistically significant the size of the effect is frequently smal1. This may be partly the result of errors in the measurement of time preference but may also indicate weaknesses in specification of the model.

For instance, the assumption that investment behavior is affected only by time preference is probably unrealistic. Investments typically involve uncertainty as well as time preference because future values of 
any variable, whether it be the price of a stock or the state of health, cannot be known with certainty. Thus, individual attitudes toward risk will also affect investment behavior. The uncertainty element is probably particularly large in the case of investments in health such as giving up cigarettes, eliminating fatty foods, jogging, and the like. Even the best information available indicates only the average expected benefit from such health investments; the return to any individual is highly uncertain. Only a minority of cigarette smokers will actually contract lung cancer, while giving up cigarette smoking does not provide a guarantee against the disease. Therefore, individual differences with respect to uncertainty can also affect health investment and health status. Psychologists Kahneman and Tversky, in their highly original and provocative work on prospect theory [1979], have suggested that most individuals prefer certain to uncertain gains, but prefer uncertainty to certainty with respect to losses. For example, most individuals, when offered a choice between A) a certain gain of $\$ 500$ or B) an equal chance to win $\$ 1,000$ or nothing, will choose $A$. The same individuals, when offered a choice between A) a certain loss of $\$ 500$ or B) an equal chance to lose $\$ 1,000$ or nothing, will choose $B$.

Such asymmetry in risk aversion, if applicable to health-related behavior, could be important. Consider a person contemplating giving up some current pleasurable activity or undertaking an unpleasant one in return for the chance of an improvement in health status sometime in the future. The immediate action involves a loss with a high degree of certainty, but the future gain is quite uncertain for the individual even though it may be highly predictable, on average, for a large population. 
Thus, the stronger the individual's asymmetry with respect to uncertainty (as described by Kahneman and Tversky), the less likely will he or she undertake the health-enhancing action. This conclusion is unaltered if one reverses the "framing" of the decision and thinks of the current activity such as cigarette smoking as a "gain" (where certainty is preferred) and the possibility of $i 11$ health in the future as the "loss." Thus, individual differences in risk aversion may confound attempts to measure time preference or to analyze the effects of time preference on health.

This survey and the analyses reported here also highlight problems of measurement of health status and health investment. When health is measured by subjective self-evaluation, the results are different from those that are obtained when a composite health measure based on selfevaluation, medical care utilization, symptoms and physical ability is used. Problems in the measurement of health investment surface when we examine a variable like exercise. It seems as if exercise is undertaken for many reasons other than to improve health. These other reasons may swamp an effect of time preference. Perhaps more detailed questions concerning the type and intensity of exercise would help.

I conclude this report of exploratory research on a note of cautious optimism. Crude but useful measures of time preference, health investment, and health status can be obtained, even through very inexpensive telephone interviews. Time preference is related to schooling, and also shows some relation to health investment and health status. However, none of the relationships found in these data are particularly strong. Whether improvements in survey design, more accurate measurement of variables, and better specification of models will produce more significant results remains to be determined. 


\section{FOOTNOTES}

1. For a bibliography which covers sources from both disciplines, see Maital and Maital [1978].

2. For an excellent summary of present knowledge in this field as well as many useful bibliographies, see Healthy People, The Surgeon General's Report on Health Promotion and Disease Prevention, Background Papers, U.S. Department of Health, Education, and Welfare (PHS) No. 7955071A, Washington, D.C., U.S. Government Printing office, 1979.

3. There are, to be sure, many other possible explanations for the correlation between schooling and health. For instance, persons with better health endowments may be more efficient in schooling activities, or their expected rate of return to schooling may be higher because of their greater life expectancy. Conversely, the rate of return to investment in health may be greater for those who have had more schooling. This paper does not address all possible explanations; it focuses on differences in time preference.

4. "When habits are once formed, they regulate the tenor of the future life, and make slaves of their former masters." John Rae, The Sociological Theory of Capital [1834] (C. W. Mixtor, ed.), New York: Macmillan, 1905, as quoted in Shlomo and Sharona Maital [1978].

5. William Hazlitt wrote in The Round Table [1817], "Persons without education. . see their objects always near, and never in the horizon." And Robert Penn Warren wrote "Without the fact of the past, we cannot dream the future." ("Brother to Dragons," a poem.)

6. I am grateful to Alan Garber and Richard Zeckhauser for helpful comments on this point.

7. Temporal orientation refers to the point in time about which a person's thoughts tend to center and to the volume of those thoughts. 
8. The questionnaire was administered by psychologists at Perceptronics in Eugene, Oregon.

9. Stephen Cole also made many contributions to the design of the questionnaire.

10. A digit-raising technique was used to insure inclusion of unlisted numbers.

11. See Appendix A for a list of time preference questions.

12. I am grateful to Amos Tversky for advice on this point.

13. Approximately one-quarter of the respondents classified as consistent chose "now" for all six questions and another one-quarter always chose to wait. Their replies, while not inconsistent, are not as informative about consistency as the replies of those respondents who chose "now" for some questions and "wait" for others.

14. Given six questions, every possible set of replies can be made consistent with a maximum of three reversals.

15. This hypothesis was suggested by Phillip Farrell.

16. Ceteris paribus, individuals with low rates of time discount might accumulate more savings, might choose occupations with larger on-the-job investment opportunities, etc.

17. For example, a respondent who answered "now" to the first four questions in Table 1 and "wait" to the next two, was assigned a rate of 35.35 percent.

18. A different set of values, based on a regression with a different sample, yielded almost identical results to those reported here.

19. Grossman's regression (for middle-aged males) comparable to Regression 2 in Table 8, Part A, had a coefficient of .035 for schooling and -.017 for age. 
20. No hospitalization in past year, no prescription drugs in past week, no medical condition requiring regular visits to physician, and fewer than three visits to physician in past six months. To be sure, medical care utilization may reflect factors such as income and insurance coverage as well as health status.

21. The weak effect of schooling is attributable to the "symptoms" and "utilization" measures of health status. When these measures are used as dummy dependent variables in regressions equivalent to (3) in Table 8, schooling is negatively (albeit not significantly) related to good health. 
REFERENCES

Auster, Richard, Irving Leveson, and Deborah Sarachek [1969], "The Production of Health, an Exploratory Study," The Journal of Human Resources, Vo1. 9 (Fa11), 412-436.

Becker, Gary S. [1964; 2nd ed. 1975], Human Capital, New York: Columbia University Press.

Fuchs, Victor R. [1967], "The Basic Forces Influencing Costs of Medical Care," address given at the National Conference on Medical Care Costs, Washington, D.C., June 27, 1967.

Grossman, Michael [1972], The Demand for Health: A Theoretical and Empirical Investigation, New York: Columbia University Press for the National Bureau of Economic Research.

Grossman, Michael [1975], "The Correlation between Health and Schooling," in Nestor E. Terleckyj (ed.), Household Production and Consumption, Studies in Income and Wealth, Vol. 40, Conference on Research in Income and Wealth. New York: Columbia University Press for the National Bureau of Economic Research. Maital, Shlomo, and Sharona Maital [1978], "Time Preference, Delay of Gratification, and the Intergenerational Transmission of Economic Inequality: A Behavioral Theory of Income Distribution," in Orley Ashenfelter and Wallace Oates (eds.), Essays in Labor Market Analysis, New York: John Wiley.

Metcalf, Charles E. [1974], "Predicting the Effects of Permanent Programs from a Limited Duration Experiment," The Journal of Human Resources, Vo1. 9 (Fa11), 530-555. 
Kahneman, Daniel, and Amos Tversky [1979], "Prospect Theory: An Analysis of Decision under Risk," Econometrica, Vol. 47, No. 2 (March), $263-291$.

Thaler, Richard [1979], "Individual Intertemporal Choice: A Preliminary Investigation," Research Memorandum (mimeo).

Thomas, Ewart A. C., and Wanda E. Ward [1979], "Time Orientation, Optimism, and Quasi-economic Behavior," Stanford University (mimeo).

U.S. Department of Health, Education, and Welfare [1979], Healthy People, The Surgeon General's Report on Health Promotion and Disease Prevention, Background Papers, (PHS) No. 79-55071A, Washington, D.C.: U.S. Government Printing office. West, Richard W. [1978], "The Rate of Time Preference of Families in the Seattle and Denver Income Maintenance Experiment," SRI Internationa1, Research Memorandum 51. 
Appendix Exhibit 1

TIME PREFERENCE QUESTIONS

A. Implicit interest rate

Given your present circumstances, suppose you won a taxfree prize at a local bank and were offered a choice between two prizes. I am going to read off pairs of choices and for each pair you tell me which prize you would choose.

28. $1=\$ 1,500$ now, or

$2=\$ 4,000$ in 5 years

29. $1=\$ 1,000$ now, or

$2=\$ 2,500$ in 3 years

30. $1=\$ 4,000$ now, or

$2=\$ 6,000$ in 4 years

31. $1=\$ 750$ now, or

$2=\$ 1,250$ in 1 year

32. $I=\$ 2,500$ now, or

$2=\$ 4,000$ in 3 years

33. $1=\$ 500$ now, or

$2=\$ 2,500$ in 4 years

$$
\begin{aligned}
& \text { DON'T }[3=\text { don't know } \\
& \text { READ }[9=\text { refuse } \\
& \text { DON'T }[3=\text { don't know } \\
& \text { READ }[9=\text { refuse } \\
& \text { DON'T }[3=\text { don't know } \\
& \text { READ }[9=\text { refuse } \\
& \text { DON'T }[3=\text { don't know } \\
& \text { READ }[9=\text { refuse } \\
& \text { DON'T }[3=\text { don't know } \\
& \text { READ }[9=\text { refuse } \\
& \text { DON'T }[3=\text { don't know } \\
& \text { READ }[9=\text { refuse }
\end{aligned}
$$

B. Explicit interest rate

34. Suppose you won a tax-free prize of $\$ 10,000$ at a local bank. You then had a choice between getting the money now or leaving it in the bank for one year. How much interest would the bank have to pay you in order for you to agree to leave the money in the bank? [CASCADE--STOP READING IHHEN CHOICE

$$
\begin{aligned}
& 1=68 \\
& 2=88 \\
& 3=108 \\
& 4=158 \\
& 5=208
\end{aligned}
$$
MENTIONED]

$$
\begin{aligned}
6 & =308 \\
7 & =508 \\
8 & =\text { take the money now } \\
\text { DON'T } 19= & \text { don't know } \\
\text { READ } & \text { or refuse }
\end{aligned}
$$


C. Attitudinal questions

Do you agree or disagree with the following statements?

$$
\begin{aligned}
& \text { (Categories for Questions } 35 \text { to } 38 \text { ) } \\
& 1 \text { = agree } \quad 2=\text { disagree } \quad \text { DON'T }[3=\text { don't know } \\
& \text { READ } \quad \text { l }=\text { refuse }
\end{aligned}
$$

35. Parents should make financial sacrifices in order to save money for their children's education.

36. It makes more sense to spend your money now rather than saving it for the future.

37. A working man should have life insurance equivalent to at least three times his annual income even if paying for this insurance means he would have to live on a tight budget.

38. Most people spend too much time worrying about the future and not enough time enjoying themselves today.

D. Expected inflation

39. In general, during the coming year do you expect prices to:

1 = decrease

2 = stay abcut the same

3 = increase by about 5 percent

4 = increase by about 10 percent

5 = increase by about 15 percent

6 = increase by about 20 percent

7 = increase by about 30 percent or more

DON'T $[8=$ don't know

READ $[9=$ refuse

E. Use of credit

54. At the end of each month do you usually pay the balance on all your outstanding credit cards, or do you have a debit balance on which you must pay interest?
1 = pay all balances
2 = have debit balance
3 = have no credit cards
DON'T $\left[9=\right.$ don't $^{\prime}$ know
READ or refuse

55. When you or your spouse buy a car, do you pay cash or take a car loan?

$1=$ pay cash

2 = take a car loan

3 = have done both in the past

$4=$ never buy cars

$\underset{\text { READ }}{\text { DON'T }}[9=$ refuse 
Appendix Table A. Zero-order correlations among selected variables.

\begin{tabular}{lccccccc}
\hline \hline & SCHOOL & HSRANK & PARED & LIVPAR & ADJINC & IMPINT & EXINFL \\
\hline SCHOOL & -- & .47 & .37 & .21 & .25 & -.23 & -.05 \\
HSRANK & .33 & -- & .21 & .09 & .15 & -.11 & -.03 \\
PARED & .30 & .19 & -- & .02 & .29 & -.07 & .01 \\
LIVPAR & .20 & .10 & .15 & -- & .07 & .02 & .02 \\
ADJINC & .27 & .09 & .14 & -.04 & -- & -.23 & .01 \\
IMPINT & -.03 & .03 & -.21 & .02 & -.02 & -- & .19 \\
EXINFL & .18 & -.01 & .03 & -.05 & -.06 & .03 & -- \\
& & & & & & &
\end{tabular}

Females: upper right triangle.

Males: lower left triangele.

$r \geq|.21| \mathrm{p}<.01$

$r \geq|.17| \mathrm{p}<.05$ 